\title{
PHYSIOTHERAPY AND NEURAL INVOLVEMENT IN LEPROST:
}

Ruth E. ThOMAs, S.R.N., M.C.S.P.

Many people do not realize how precious to them are the everyday functions of the hand that they take for granted. To be able to button up clothes, tie shoe laces, hold a spoon or glass, use a pen, or sew with a needle means independence. It is only possible to perform these actions because we have a brain to direct and two hands to carry out this direction. If these simple things cannot be done with one's hands then we must depend on someone else to do them for us.

This hand function that is taken so much for granted is the result of an extremely intricate and finely balanced system of many small and large muscles, tendons, and joints. Anything that disturbs a part of this finely balanced mechanism, no matter how small or insignificant it seems, results in a change in the appearance and function of the hand. The loss of even a part of the 20 small muscles of the hand may cause a serious imbalance in the hand which greatly reduces its usefulness. Many injuries and disease processes are the cause of the upsetting of the finely-balanced hand, and leprosy, by its involvement of the nerves, is one of these insidious but relentless enemies of our invaluable hand function.

For the past two years different forms of physiotherapy have been used at the leprosy clinic of the Christian Medical College Hospital, Vellore, South India. The aim has been to try and find out just what physical therapy can do for people with neural involvement in leprosy. A variety of cases-men, women and childrenhave received physiotherapy. From our experience we feel that there are three phases associated with the physiotherapy work:-

A. The mental state of the patient needs to be considered.

B. Physical treatment for the hands.

C. Rehabilitation.

\section{A. The Mental State of the Patient.}

For physiotherapy, or indeed any treatment, in leprosy to be successful, the psychological outlook of the patient is of the utmost importance. It had been found that most patients with some paralytic trouble of the hand or deformity of the fingers have given up their work when this paralysis or deformity began, or shortly after it commenced. This was sometimes due to the fact that the patient 
himself felt this weakness and therefore felt he could no longer cope with his work, or it was sometimes because his employer had no use for a person with weak hands; or (and this was the worst reason of all from the psychological aspect of the patient) it was sometimes because no one would employ a person with leprosy. But, whatever the reason, the fact that the patient has had to give up his work tends to make him feel that he is no use to himself or anyone else, and that he is a burden to his family and society, with the result that he resigns himself to his condition and loses the will to help himself.

The main aim, therefore, is to win the confidence and cooperation of these people, and try to help them to help themselves, and to show them that weak or deformed though their hands may be they can, with care and practice, do much to help themselves. They must learn to realize that they cannot do many things as well as the normal person, and that their movements are necessarily slower because of their disability. In some way they must be taught to accept all this, and at the same time be encouraged to use what is left; and to learn that there are many things that they can, with practice, get to do as well as a perfectly normal person. The important point to remember is not to give them anything to do which is beyond their capabilities, for that will discourage rather than encourage them.

\section{B. Physical Treatment for the Hands.}

The patients who come for treatment have varying degrees of deformity, but they all conform to a uniform pattern. Usually the intrinsic muscles in the hand supplied by the ulnar nerve are the ones to become paralysed first:-

Muscles of the hypothenar eminence.

Dorsal and palmar interossei.

3rd and $4^{\text {th lumbricals. }}$

Adductors obliquus and transversus pollicis.

Opponens and abductor brevis pollicis.

Very often the intrinsic muscles in the hand supplied by the median nerve are also involved:-

Opponens and abductor brevis pollicis.

Ist and 2nd lumbricals.

Paralysis of these muscles gives rise to flexion of the interphalangeal joints and hyperextension of the metacarpophalangeal joints, (main en griffe or claw-hand) and the thumb falls back to lie in the same plane as the palm. If these deformities are allowed to continue without physiotherapy, the flexion progresses to an irreversible contracture of the joints. 
Amongst our patients are some very early cases with little or no flexion deformity, and certainly no contracture, but who have a slight degree of paralysis and atrophy of some of the intrinsic muscles of the hand resulting in weakness. With these people the aim was to try and prevent further atrophy of these muscles and to improve their condition as far as possible.

Other leprosy patients who attended for treatment had some deformity-either flexion deformity with no contracture, the patient being unable to extend his fingers actively though they could be extended passively; or flexion deformity with joint capsule contracture in some cases, and a contracture due to skin tightness in other cases, but in neither case could the fingers be fully extended actively or passively. With these people the aim was to try and loosen the stiff joints, or at least maintain the existing range of movement.

Several methods of physiotherapy have been used on a number of patients with varying degrees of paralysis and deformity. Careful records have been kept, and the results seem to indicate that physiotherapy is of great value in neural leprosy. The methods used have been:-
I. Oil Massage
2. Wax Therapy
3. Electrical stimulation

Each type of treatment was always followed by active exercises, and these were considered the most important part of the treatment.

\section{Oil Massage.}

The patient is given a little groundnut oil to rub over his hands and then instructed to massage his fingers in a downward direction, i.e. from metacarpo-phalangeal joint to finger tip. The aim is to straighten the fingers, and the massage done in a downward direction seems to straighten them better than when done in an upward direction. This type of oil massage was found to be of value because:-

(I) It is done by the patient himself, and could therefore be carried out by patients in their own homes, so it was useful for people who lived a long distance away and could not attend for treatment more than once or twice a week.

(2) Where there was flexion deformity of the fingers, but no contracture, it helped to maintain the mobility of the fingers and prevent them becoming contracted.

(3) Where there was some degree of contracture, and this contracture was due to skin tightness, regular daily massage helped to straighten the fingers gradually. Where there have been failures in straightening contractures this has probably been because either 
the contracture was due to bony changes in the joint or to dense fibrous adhesions.

\section{Wax Therapy.}

Paraffin wax packs can be applied by dipping the hands a number of times in fairly quick succession into the bath of melted wax. Each coating should be allowed to congeal slightly before the next dip, and should be kept intact, as it is important that all air should be excluded. When the complete coating is $\frac{1}{8}-\frac{1}{4}$ " thick, the hand is wrapped in grease-proof paper and then in blanket material to preserve the heat. The patient is asked to keep the hands as still as possible to avoid any cracking of the wax glove.

The temperature at which the wax packs are applied varies from $120^{\circ} \mathrm{F}$ to $130^{\circ} \mathrm{F}$, beginning with the lesser heat and increasing the temperature of the wax as the treatments progress. For a person with a normal skin it is possible to increase the temperature to $140^{\circ} \mathrm{F}$ with safety, but as most leprosy patients have anaesthesia of the skin to a greater or lesser degree, they are not given these packs at any temperature over $130^{\circ} \mathrm{F}$, and that has proved a safe maximum. The pack is left on for 15-20 minutes, at the end of which time the wax glove is quite easily peeled off, and active hand and finger exercises are done.

This treatment increases the heat and circulation of the part to which the pack is applied, so that on removal of the pack the fingers feel more mobile and are better able to do the active exercises which follow. It has been found very useful for stiff joints, and the patients who have attended regularly for this treatment have also noticed that their joints have become looser and that consequently their hands are more useful. Most of the patients whose joints became increasingly stiff were those who were irregular in attendance for their treatments.

It has also been found that paraffin wax packs soften hard, dry, skins, so that the skin of such hands becomes more smooth and supple. In advanced neural leprosy, patients commonly lose the power to perspire on their hands and feet. In some of these patients wax therapy seems to have stimulated the sweat glands to reactivity in some way, so that perspiration functions again. In a few patients whose hands were completely anaesthetic, a gradual return to sensation of heat has been experienced. Occasionally wax packs have been prescribed for relief of pain in the fingers with good results.

Requirements :-

Thermostatically controlled wax bath, or two aluminium or 
enamelled wash basins of different sizes with electric hot plate or oil stove.

Refined paraffin wax-which can be bought in blocks.

Grease-proof paper.

Blanket material.

Bath thermometer.

\section{METHOD :-}

If the thermostatically controlled wax bath is not obtainable, two wash basins of different sizes can be used. Water is placed in the larger bowl, and the smaller bowl containing the paraffin wax is placed in the water. The whole is placed on some kind of heater. An electric hot plate is best, but if electricity is not available, an oil stove can be used. If the latter is used extreme care should be taken while the stove is alight, as wax is inflammable.

The patient's skin should be examined before each treatment for minor abrasions, cuts, etc. If such are present the treatment is not necessarily contraindicated, but they should be covered with adhesive plaster.

\section{Temperature:}

As has already been stated, this should be between $120^{\circ} \mathrm{F}-130^{\circ} \mathrm{F}$, beginning with the lesser heat and increasing the temperature of the wax as the treatments progress. $130^{\circ} \mathrm{F}$ has proved a safe maximum.

The part to be treated may be dipped 8-Io times in fairly quick succession into the bath of melted wax. Each coating should be allowed to congeal slightly before the next dip, and must be kept intact, as it is important that all air should be excluded. When the final layer of wax has been applied, the hand is wrapped in greaseproof paper and then in blanket material to preserve the heat. The patient should be asked to keep the hand as still as possible to avoid any cracking of the wax glove.

Duration: From I5-20 minutes, at the end of which time the wax glove is quite easily peeled off and put back in the wax bath. Then active exercises are done by the patient.

\section{UsES :-}

I. The heat and circulation of the hand are increased so that the fingers feel mobile, and are better able to do the active exercises which follow-wax therapy is therefore useful as an aid to loosening stiff joints.

2. Hard, dry, and horny skins become smooth and supple.

3. In some patients whose sweat glands have ceased to function for a long time wax therapy seems to stimulate them to re-activity in some way, so that perspiration functions again. 
4. In some patients whose hands were completely anaesthetic, a gradual return of sensation to heat has been experienced.

5. Relief of pain.

\section{Electrical Stimulation.}

Faradic and galvanic currents both possess the power to stimulate the excitable tissues, and their therapeutic properties are due, directly or indirectly, to this power. For example, when a muscle is weakened by injury or disease it can be strengthened by being artificially exercised by electrical stimulation. Rhythmic contraction and relaxation of a muscle not only exercises it, but it increases its circulation, and also has the effect of loosening fibrinous adhesions, and aiding the removal of exuded fluid. When reaction of denervation is present the infrequently interrupted or surging galvanic current is generally used, but if the reaction is of the normal type, the faradic current is usually employed, as these currents procure contraction of the weakened or paralysed muscles.

If a nerve is affected by disease, and this disease is gradual in its onset, at first it may not damage the nerve fibres, but afterwards it might do so. Also, the disease might not involve all the nerve fibres at first, but it might do so later, in which case the process of denervation is gradual. This appears to be so in leprosy where there is nerve involvement. Quite often the ulnar nerve on palpation at the elbow will be felt to be thickened, but apart from the patient experiencing pain along the course of the nerve, or being aware that some areas of skin are anaesthetic, there is often no immediate weakening in the hand or atrophy of muscles supplied by this nerve. In fact, degeneration causing atrophy of muscles and weakness of movement sometimes takes many months to become apparent.

The main aims in using electrical stimulation were:-

(a) To strengthen the muscles.

(b) In the event of gradual denervation to work the muscles for the patient and maintain their muscle tone, always hoping that after the period of denervation there would be a period of regeneration. Where this occurred, because the tone of the muscles had been maintained, the muscles should done and

(I) regain their strength more quickly than if nothing had been

(2) the possibility of flexion deformity and contracture occuring during the period of denervation was more likely to be delayed and possibly averted altogether.

In the very acute phases where the patient has severe pain, 
it is best not to give electrical stimulation until this pain has subsided, for in such cases the condition would probably become worse (due to the stimulation) instead of improving.

Therefore, for this type of treatment early cases of motor nerve involvement in leprosy were chosen. That is, cases where there was muscle weakness, but little or no flexion deformity or contracture. From the records that have been kept it appears that electrical stimulation is beneficial in the majority of cases. But our observations also show that short periods of treatment are of little value, and that both the patient and physiotherapist must have patience to continue the treatment over a long period of time.

\section{Exercises.}

Although oil massage, wax packs, and electrical stimulation are useful as preliminary treatments, the stress is laid on exercises. The group of exercises used can be divided into 3 sections:-

Partly-passive, partly-active exercises

Assisted active exercises

Free active exercises

\section{PARTLy-PASSIVE, PARTLY-ACTIVE EXERCISES :}

As the majority of patients have no sensation of pain, this type of exercise needs to be done with extreme caution. It has a value providing it is done with great care, and that it is understood that it may produce increasing fibrous adhesions if done too violently, so that very careful supervision is required. Where there is flexion deformity but no contracture, the aim is to straighten the fingers passively and so maintain their full mobility. In such cases the precaution necessary is that of preventing hyperextension of any joints during the exercise. Where there is contracture of the fingers the aim is to decrease it by gradually loosening the stiff joints by passive stretching. It is in this type of case that extreme care and supervision is required, so that the passive part of the exercise does not become a strong forced passive movement.

\section{EXAMPLES OF EXERCISES :}

(I) Clasp the hands together, palms facing the body, and press the fingers towards the body, care being taken not to hyperextend the metacarpo-phalangeal joints. Then separate the hands, keeping the fingers as straight as possible while doing so. This exercise begins with a passive stretching of the fingers and ends with an effort on the part of the patient to keep the fingers straight.

(2) Place the hands, palms facing downwards, on a flat surface, and try to straighten the fingers. Light careful pressure may be given with the other hand to any fingers which cannot straighten without assistance. In this exercise the patient first makes the effort 
to straighten the fingers, and if this straightening is incomplete, the other hand is used to try to complete the extension passively. In flexion deformity this is possible and no special caution is needed. But if contracture is present, then the pressure must be given lightly and with great care in order to avoid a forced passive movement, for such a movement could easily overstretch the contracting tissues. And even if it gives a temporary improvement it might well, in the long run, produce more adhesions from the multiple microscopic bleeding that might result by using too much force.

Some patients have a tendency towards ulnar deviation of the hand, or one or more of the fingers. In an attempt to correct this the "painting" exercise was introduced. The hand and fingers are kept still, but the forearm moves in the ulnar direction, and this pushing movement helps to correct the ulnar deviation.

\section{Assisted ACtive Exercises :}

In an assisted movement the aim is to help a patient to perform actively an exercise that he is unable to do freely, e.g. lumbrical action:-

Place the hands and forearms on a flat surface, palms facing upwards. Flex the metacarpophalangeal joints till there is a right angle between the palm of the hand and the fingers, then straighten the hand. The fingers should be kept straight throughout the exercise. If the patient is unable to do this exercise freely, the assisted method should be used.

Place the dorsal aspect of the fingers on a flat surface, the right angle between the palm and fingers should be maintained keeping the proximal phalanges in contact with the surface and at the same time exerting slight pressure in this region, bend and stretch the interphalangeal joints.

Therefore this can be a free active or an assisted exercise. If the patient is able to do this exercise freely, it means that his lumbrical muscles are functioning normally and that his grasp of objects is of a good range. But if assistance is required it means that the nerve supply to the lumbricals is lacking and they have become atrophied and lost their power of movement so that his grasp is of very small range. In these cases it is extensor communis digitorum which extends the interphalangeal joints, and flexors sublimis and profundus digitorum which flex the fingers, thereby maintaining the lumbrical movement which is essential for a good grasp.

Where the lumbrical muscle to any finger is no longer functioning, if a patient can learn to hyperextend the proximal interphalangeal joint of that finger, he may be able to maintain that hyperextended position while his metacarpophalangeal joint is being 
flexed. In such a case the extensor communis digitorum is maintaining the hyperextension of the interphalangeal joint while the flexor sublimis digitorum is flexing the metacarpo-phalangeal joint. This trick is a useful one, and helps to improve the grasp of the patient who has this kind of paralysis.

Another assisted active exercise is that of flexing the fingers into the palm, and letting the thumb move lightly over the fingers from index finger to little finger. This is mainly an active exercise, but is regarded as an assisted exercise where there is weakness in abduction of the thumb, because the position of the fingers helps to keep the thumb in abduction during the exercise. This is only possible if abduction and opposition of the thumb are normal or slightly weak. If these movements are very weak the patient can sometimes get the thumb into position, but cannot perform the full exercise.

\section{ACtive Exercises :}

Although passive and assisted active exercises have their uses, the main stress is laid on free active exercises, for in these exercises it is possible to find out just what the patient can do. These exercises also teach him to perform the various movements of the fingers, and in this way he learns to help himself, since all these movements are used in everyday life. A number of exercises have been tried, and the following are the ones that have proved most useful:-

(I) Place the forearms and hands on a flat surface, palms facing upwards. Bend the fingers to touch the palm, and then extend them as completely as possible. This is followed with flexion and extension of each finger separately, so that the weaker fingers have an opportunity to work without assistance from the stronger fingers. If there is marked flexion deformity or contracture of the fingers there is a tendency to hyperextend the metacarpo-phalangeal joints when extending the fingers. Care should be taken to avoid this hyperextension as much as possible.

(2) Place the hands palms facing downwards, on a flat surface, and perform abduction and adduction of the fingers, keeping the had and fingers flat throughout the exercise.

In the practice of this exercise it has been observed that where the first dorsal interosseous is very weak or not functioning at all, the range of abduction of the index finger seems to be fairly good among some patients who have tried hard to produce this movement.

Similarly, where adduction and abduction movements of the little finger have become weak and practically ceased, gradually the movements have again become apparent. Electrical tests show that the muscles concerned are paralysed, so the return of these 


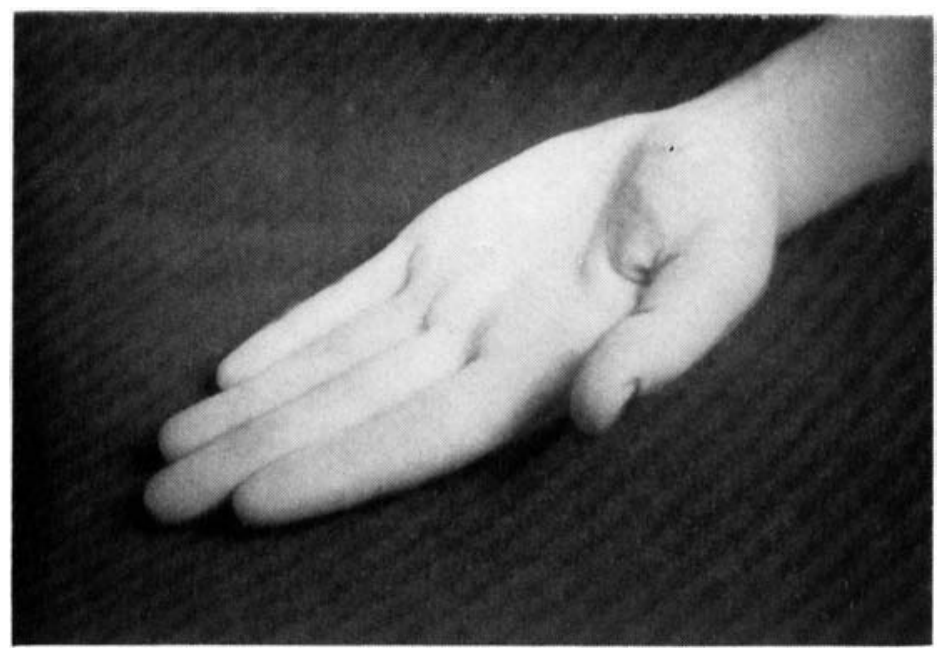

FIG. 1.

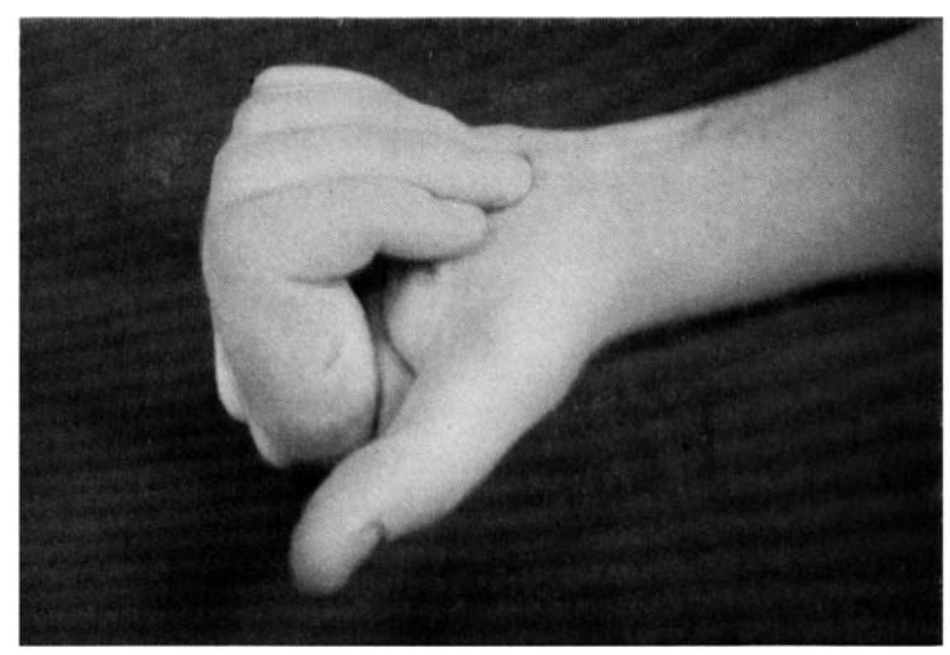

FIG. 2.

Place the forearm and hand on a table, palm facing upwards. (Fig. 1.) Bend (Fig. 2) and stretch the fingers together. (Repeat 6-12 times). Then hend (Fig. 3) and stretch each finger separatelv. (Repeat 6-12 times.) 


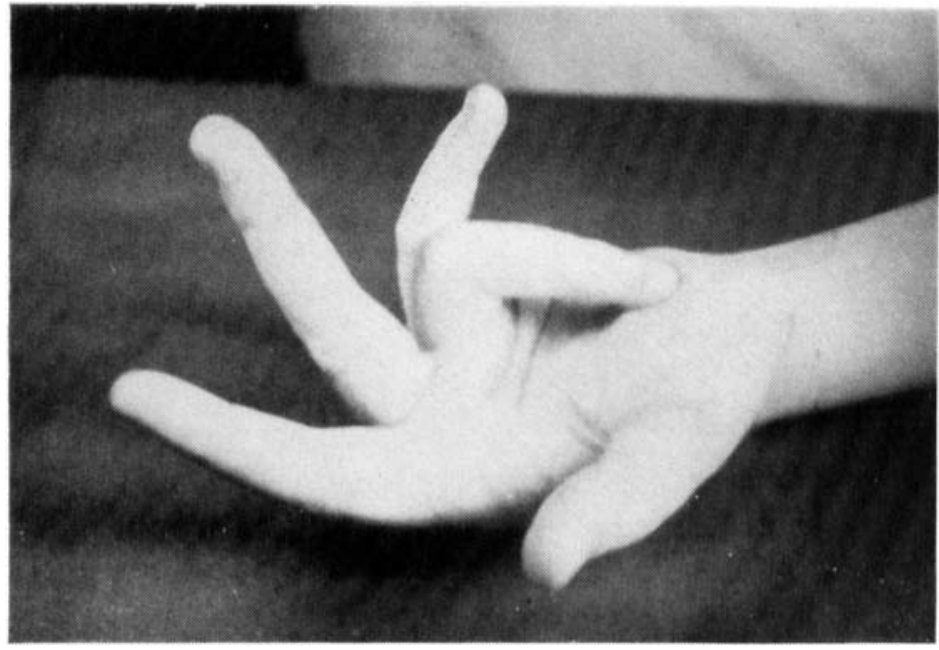

FIG. 3.

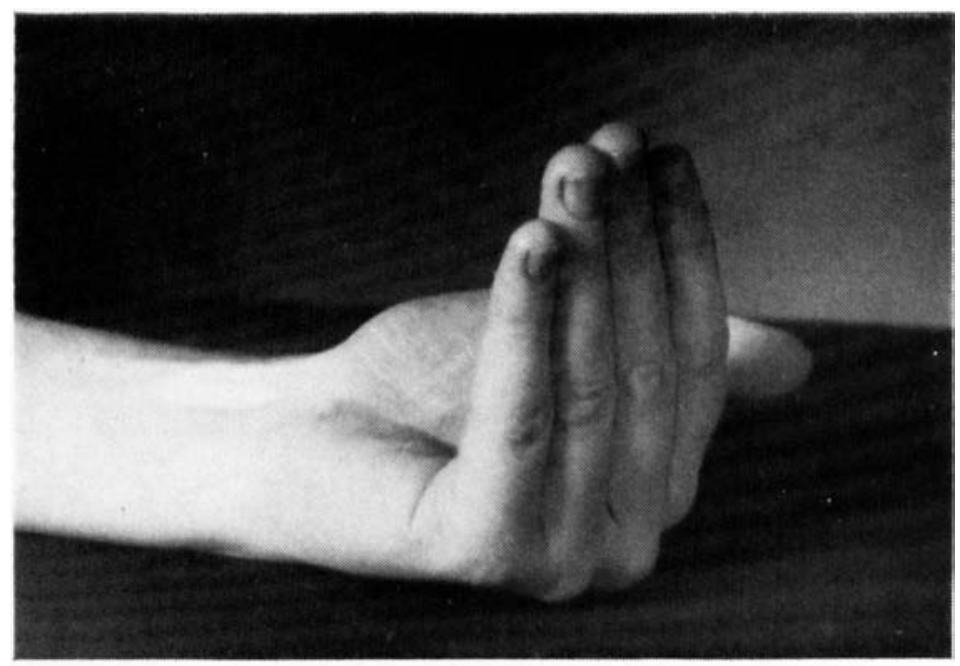

FIG. 4

(a) Same position as for Ex. 1: Bend the metacarpophalangeal joints till there is a right angle between the palm and the fingers, (Fig. 4) then straighten the hand. The fingers should he kept straight throughout the exercise. (Repeat 6-12 imes.) 
movements is due to some trick mosement, resulting in groater usefulness of the fingers concerned.

(3) Extension of the wrist plus flexion and adeluction of the fingers, followed by flexion of the wrist plus extension and abcluction of the fingers. This combination of these movements is considered natural in the normal hand. Where patients find pure abduction ancl adduction clifficult or impossible-(see previous exercise), these movements are often possible to a certain extent when performed with the other movements. Even if this exercise only maintains the limited range of abduction and adduction possible, it is worth cloing for that reason alone.

(4) With the tip of the thumb touch:-

(a) Base of each tinger in turn.

(b) Proximal interphalangeal joint of each finger in turn.

(c) I)istal interphalangeal joint of each finger in turn.

(l) Tip of each finger in turn.

The fingers should be kept straight throughout, as these exercises are mainly for abduction and opposition of the thumb. Some patients incl it difficult to perform the thumb movements while keeping the fingers flat. Where there is this difficulty it seems that there is usually a weakening of the abductor pollicis brevis muscle.

(5) I.et the thumb tip meet the tip of each finger in turn, making an "O" shape. This exercise uses all the small muscles of the hand, and emphasis is laid on making the "()" as round as possible. It has been noticed that in hands where the lumbrical muscles are functioning well, the " $\mathrm{O}$ " is a reasonably good shape. But where the lumbricals are not functioning, the fingers flex more than is required at the proximal interphalangeal joints, and the " $\mathrm{O}$ " shape is far from perfect.

(6) "Picking-up-food" movement is a form of lumbrical action, together with opposition and abduction of the thumb. The tips of all 4 fingers and thumb meet together, the thumb and fingers being kept as straight as possible. This exercise is only possir'c where the intrinsic muscles of the hand are in a fairly good functioning conclition.

Any exercise which tends to hyperextend the metacarpophalangeal joints should be discouraged, unless it can be very carefully supervised. It seems that one of the reasons why patients with claw hancls find it difficult to extend their finger joints is because the metacarpo-phalangeal joints extend or hyperextend so easily. When a patient is assisted to extend his finger joints, it is done by stabilising the metacarpo-phalangeal joint in semi-flexion, and this enables the patient to use his hand better. Some surgeons have 
fused the medacarpe-phalangea! joint in a semi-flexed position, and found that a claw hand works pretty worl after this has been done. So that in choosing exercises, those that are likely to produce undue mobility in the metacarpo-phalangeal joints should be aroided, unless they can be carefully supervised. For example, the following exercises, though they are good for certain movements of the fingers, need to be done with great caution to avoid hyperextension of the metacarpo-phalangeal joints:-

Press the elbows in at the sicles of the body, and place the palms and fingers of both hands together:-

(a) Keeping opposite finger-tips together, separate the palms and fingers and abduct the fingers, at the same time exerting slight pressure at the finger tips in orcler to straighten the fingers.

(b) Keeping opposite finger tips together and the fingers in adduction, separate the palms and fingers, at the same time exerting pressure on the finger tips.

(c) Keeping opposite palms and fingers together, abcluct and arleluct the fingers.

These exercises can be done only by patients with fairly good hands, or by patients who have the same degree of flexion cleformity or contracture in the same fingers of both hancls. Where the abcluction and adduction movements are weak in one hand, they are sometimes helped by the better movements of the other hand.

\section{SPILINTAGE.}

The use of splints has cleliberately not been cliscussed, because of insufficient experience, though it is felt that in certain conclitions splints have a clefinite part to play. But it should be borne in mincl that incliscriminate splinting is dangerous, as pressure sores are more likely to occur in anaesthetic hands than in normal hancls. Therefore cases for splintage should be carefully selected, and splints should be light and applied with caution.

\section{MEASUREMENT OE ANGLES.}

The progress of all our patients, whether unclergoing active treatment or not, was followed by periodic careful measurement of the range of movement of their fingers. It has been found that the most useful measurement to make is that of the proximal interphalangeal joint because the metacarpo-phalangeal joint is only rarely cleformed or contracted, and the terminal interphalangeal joint is not very significant. The angle that is measured is the angle by which the middle segment of the finger fails to become straight with the proximal segment of the finger. If the finger is straight 
then there is, of course, no angle or the angle si zero, but if that joint is flexed then an angle is formed.

A protractor with a moveable pointer is used for these measurements. When the pointer is parallel with the miclelle phalanx, the number at which the pointer rests is the elegree or measurement of the angle. This angle is measured under 3 elifferent types of circumstances: unassisted, assisted and passive.

To measure these angles the patient steadies his arm by resting the elbow on the table, and the forearm makes a right angle with the surface of the table. The patient is instructed to keep his wrist straight and to make a right angle at the metacarpophalangeal joint.

Unassisted angles: In this position he is told to straighten his fingers as much as possible. If he cannot straighten them, there will be an angle at the proximal interphalangeal joint. This measures the clegree of working power of the intrinsic muscles of the hancl.

Assisted angles: Using the same position, the physiotherapist exerts a little pressure on the proximal phalanx of the finger flexing the metacarpo-phalangeal joint. This gives a certain amount of support, and the patient is usually able to straighten out his finger more than when no assistance is given. This estimates the power of the long extensor muscles to extend the joint.

Passive range: The finger is passively straightened by the physiotherapist and if there is an angle it is measured. This estimates the degree of contracture of the proximal interphalangeal joint.

The following is a statistical comparison between two groups of patients which were assessed at regular intervals over a period of eighteen months. In the control group the angles of the patients' fingers were carefully measured at regular intervals, but no exercises were given. In the exercise group the patients were all on a regular scheme of exercises and the angles of their fingers measured at regular intervals.

$\begin{array}{lcccc} & & \text { Control Group } & \text { Exercise Group } \\ \text { Deteriorated } & \ldots & \ldots & 35 \% & 12 \% \\ \text { No appreciable change } & \ldots & 50 \% & 32 \% \\ \text { Improved } & \ldots & \ldots & 15 \% & 56 \%\end{array}$

It is interesting to note that the percentage of cleteriorating hands is greater in the control group, and that the percentage of improvements is greater in the exercise group, and that the majority of patients improved. 


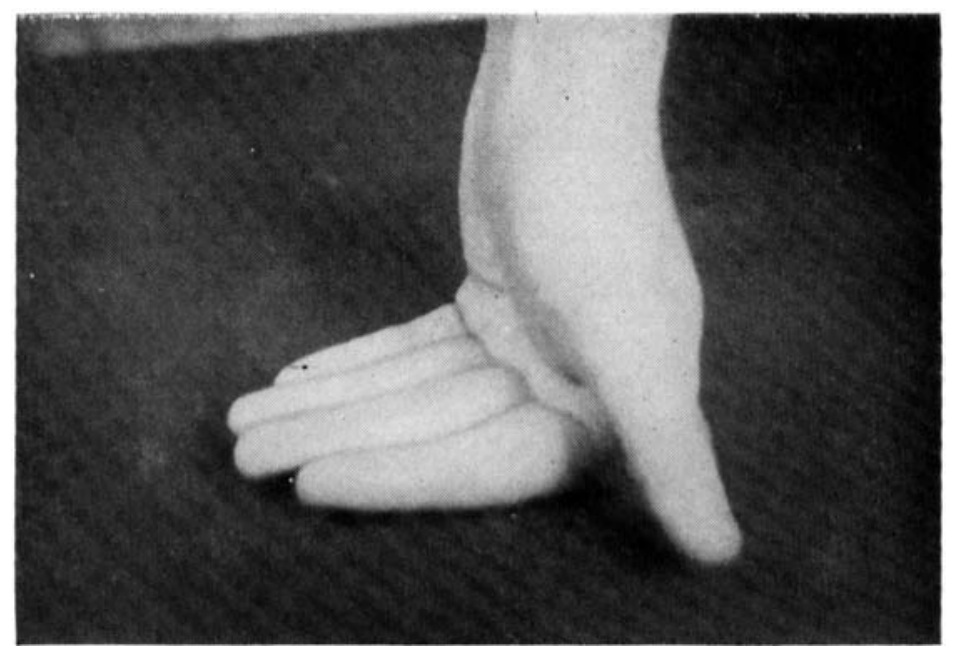

Fig. 5 .

(b) Where there is flexion deformity this will not be possible as at free exercise, so the assisted method is used: - The dorsal aspect of the fingers is placed on the table, and there should he a right angle hetween the fingers and the palm which should he maintained throughout the exercise. (Fig. 5.) Bend (Fig. 6) and stretch the interphalangeal joints of the fingers, at the same time exerting pressure on the proximal phalanges. (Repeat 6-12 times.)

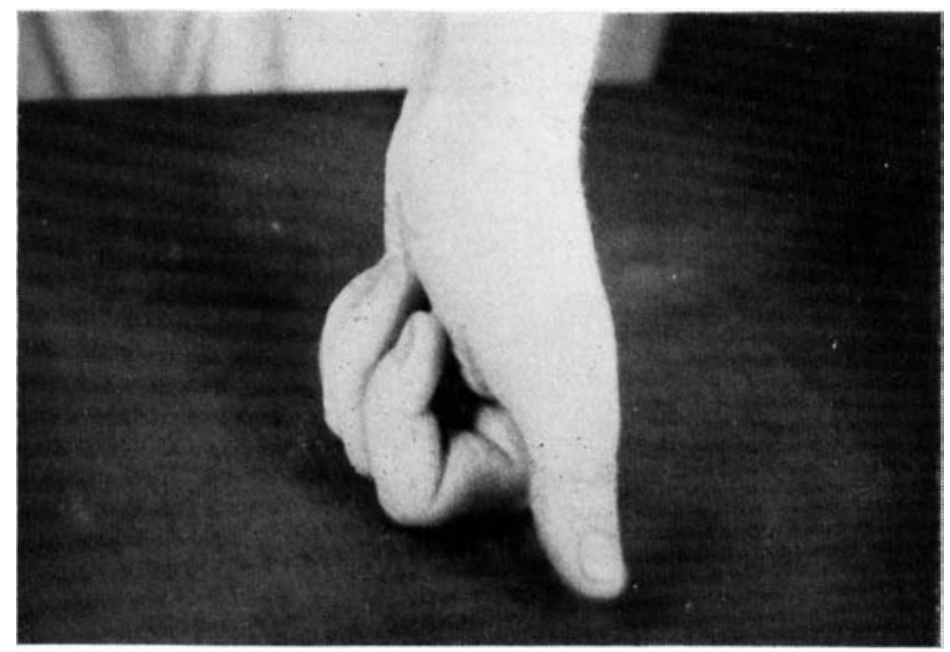

FIG. 6. 


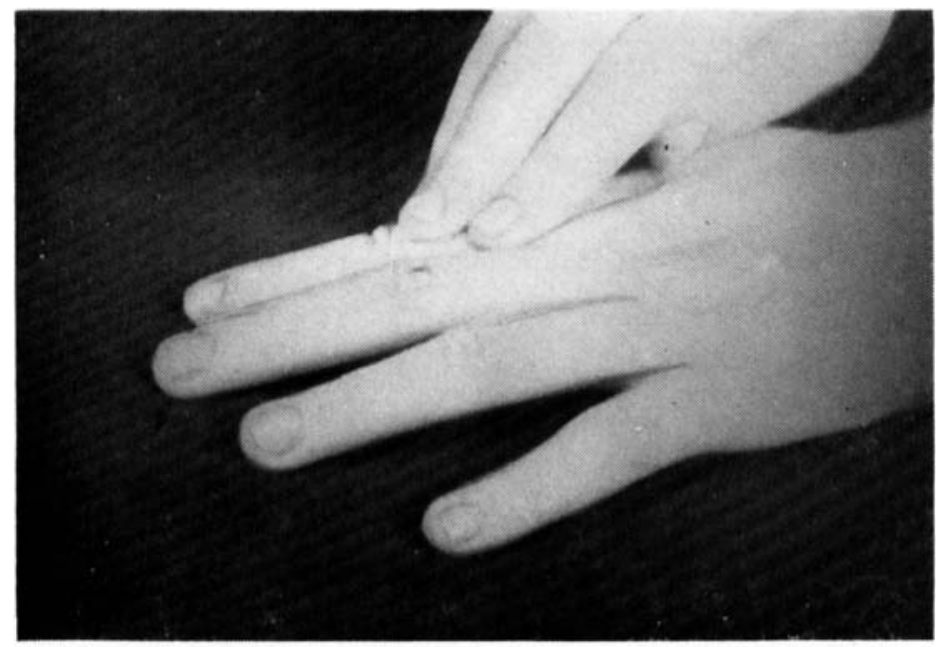

FIG. 7.

Same position as for Fx. 4: The patient should try to straighten the fingers actively. For any fingers that cannot do this, light careful pressure with the opposite hand can be exerted on the proximal interphalangeal joint of the finger in order to straighten it. (Fig. 7.) (Repeat 6-12 times.)

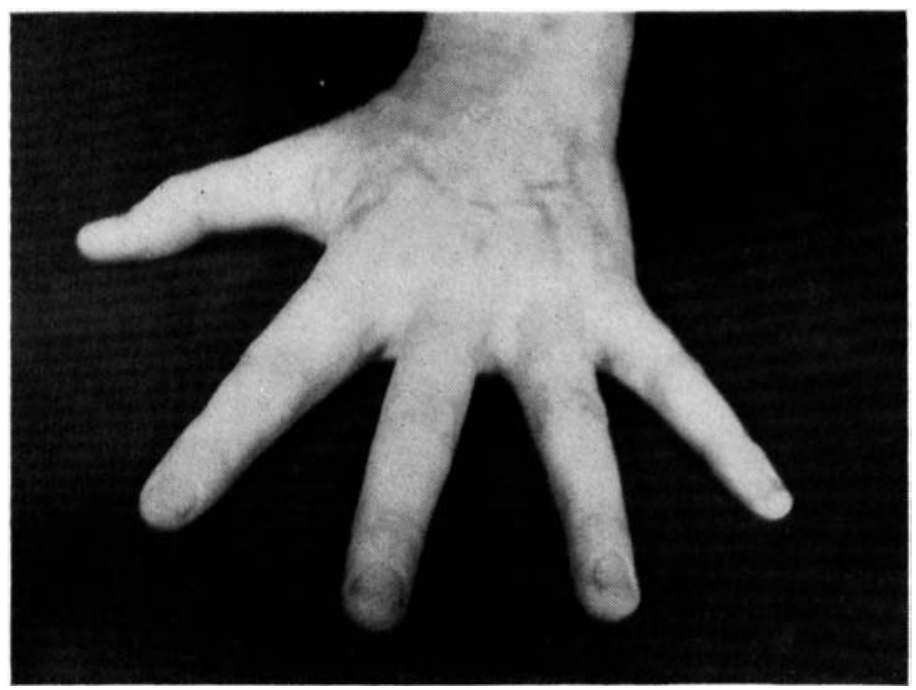

FIG. 8 .

Place the hand and forearm on the table, palm facing downwards: abduct (Fig. 8) and adduct (Fig. 9) the fingers keeping the hand and fingers straight while doing so. (Repeat 6-12 times.) 


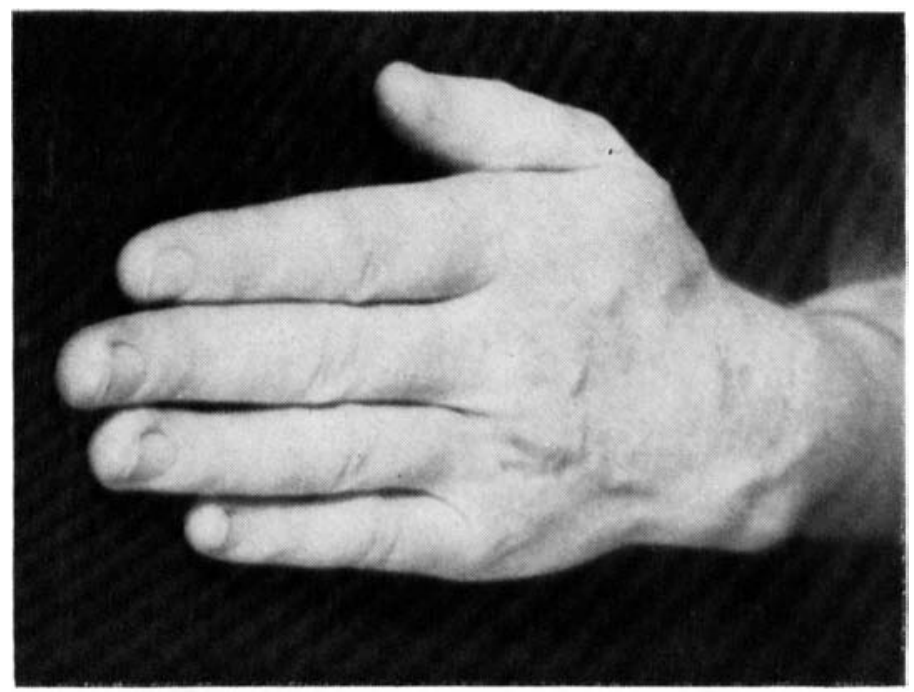

FIG. 9.

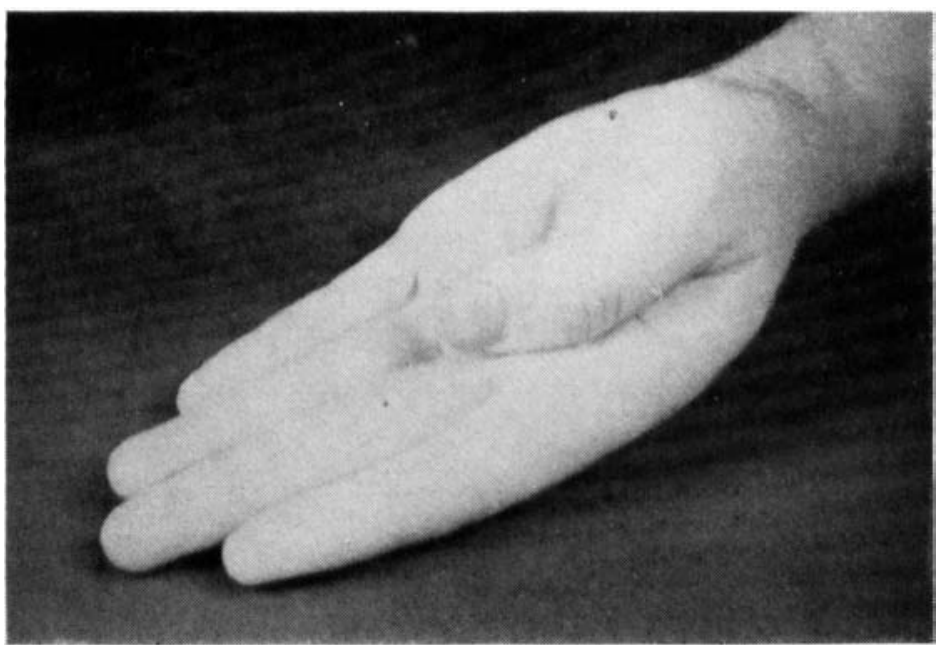

FI(i. I)

Same position as for Fx. 1: Touch the base of each finger in turn with the tip of the thumb. (Fig. 10) In between each movement the thumb should be fully extended and abducted (Fig. 11). (Repeat 6-12 times.) 


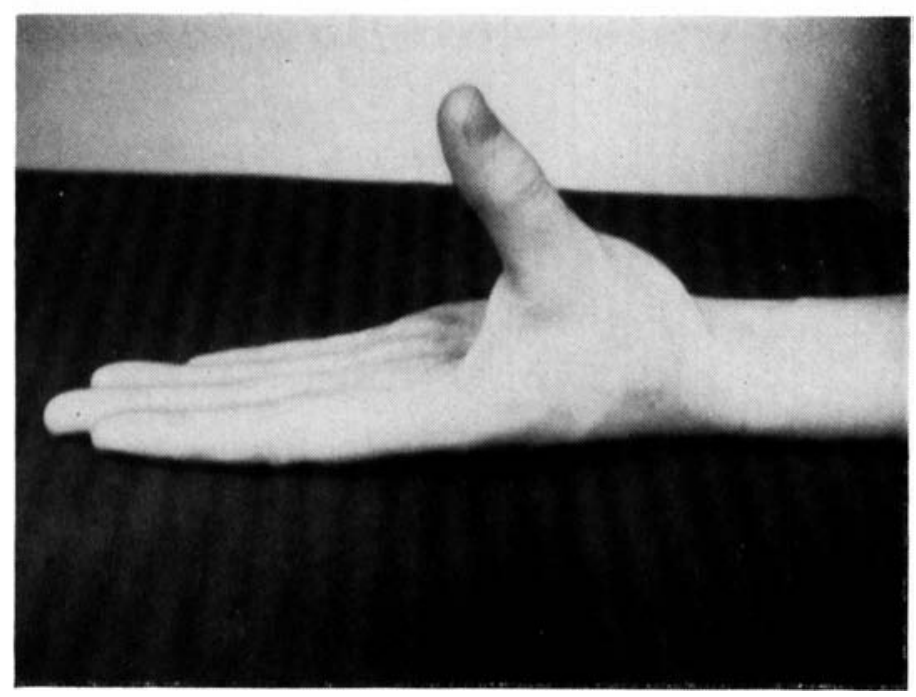

Fici. 11 .

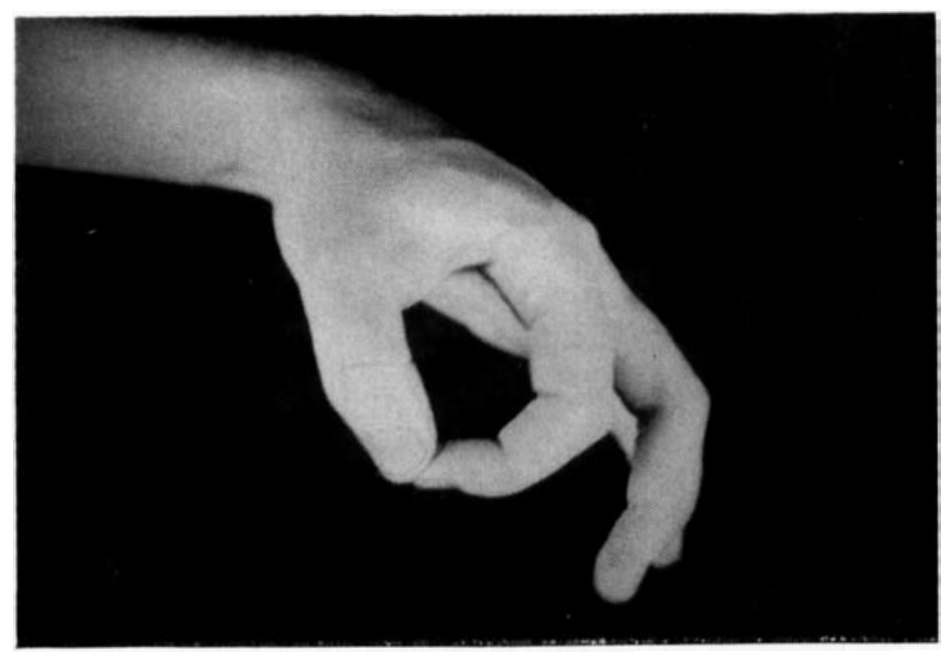

FIG. 12.

With the tip of the thumb touch the tip of each finger in turn. (Fig. 12.) In hetween each movement the thumb and fingers should he fully extended (Fig. 13). (Repeat 6-12 times.) 


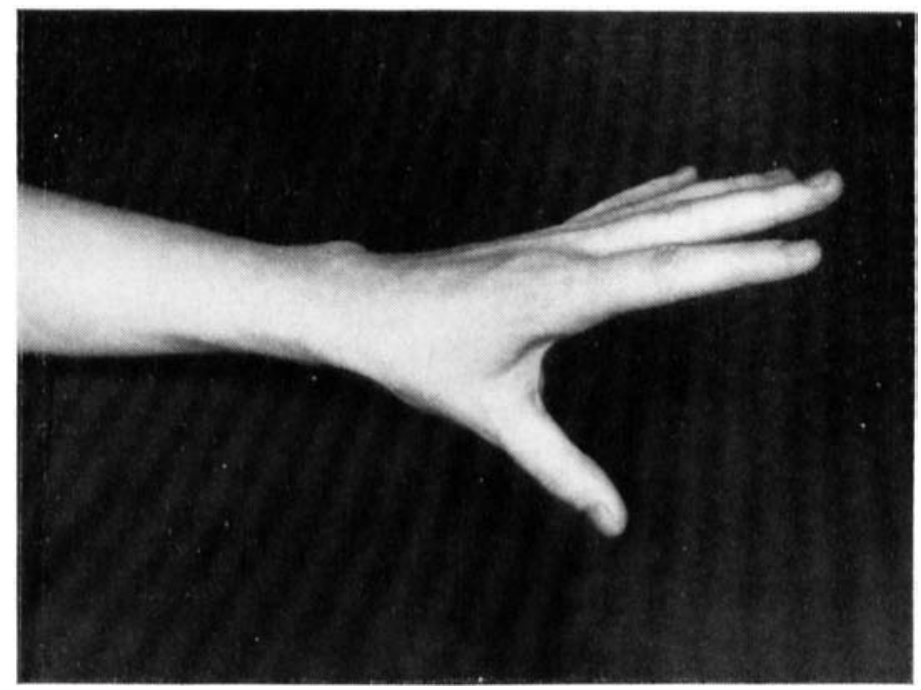

FIG. 13.

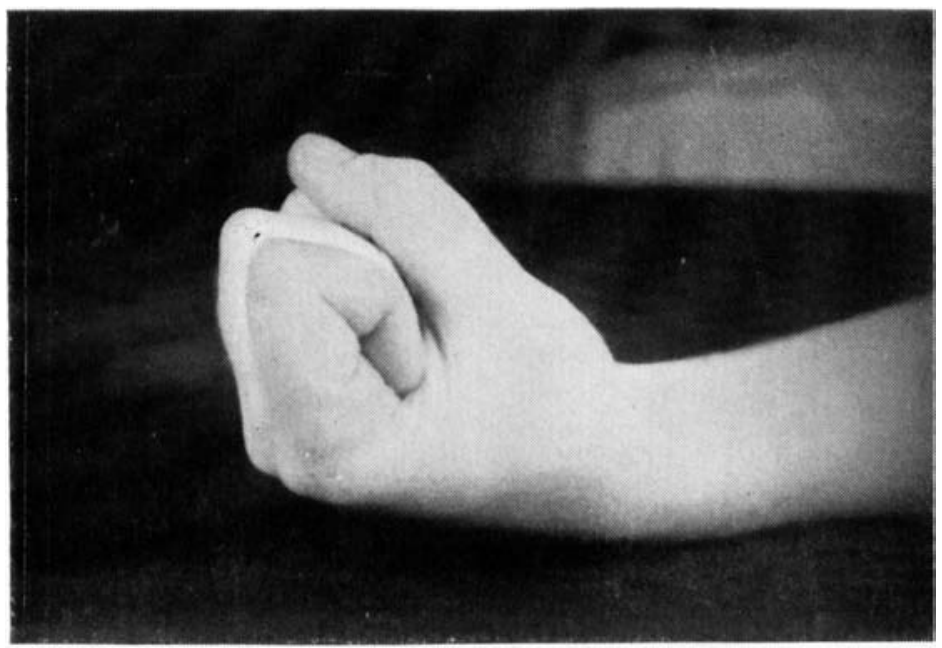

FIG. 1. f.

Make a fist with the hand and let the thumb brush lightly over the fingers from index to little finger (Fig. 14). (Repeat 6-12 timcs.) 


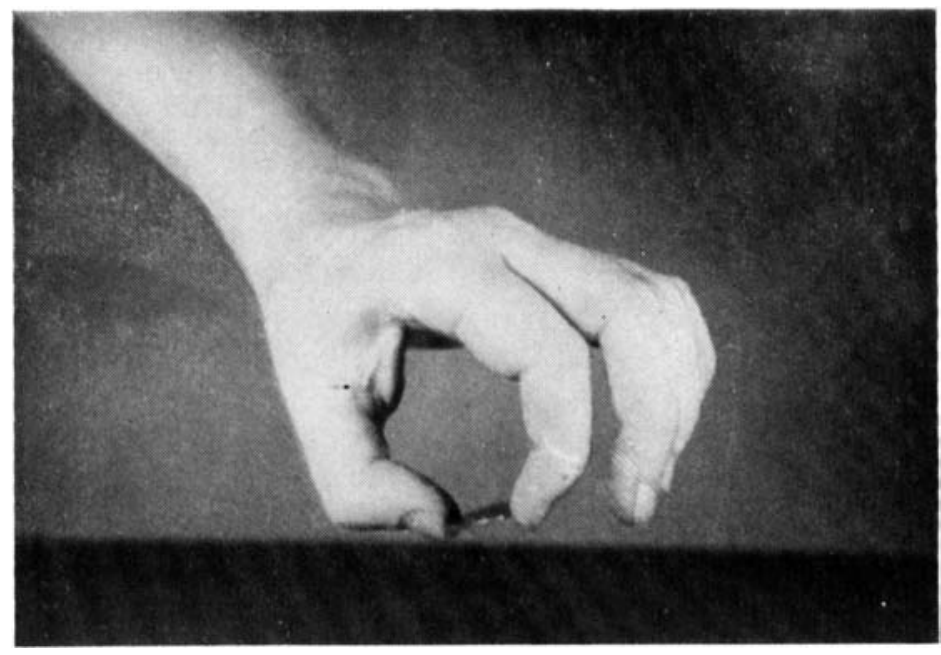

Fig. 15.

Picking up small objects of different shapes and sizes with the thumb and one finger, using each finger in turn. The thumb should use the abductionopposition position as much as possible (Fig. 15). (Repeat 6-12 times.)

Our experience in this work has shown us that short courses of physiotherapy (e.g. less than 3 months) are not sufficient to benefit a patient with leprosy. I.ong courses of treatment (at least 3-6 months, preferably longer) are necessary if physiotherapy is to be of value to the patient. Regularity of treatment is also an essential factor for improvement. Results of the past two years' work in Vellore livicle the patients into four main categories:

I. Those who improve.

2. Tinose who seem to go through a period of gradual denervalion and then a period of regeneration. Because the treatment has been regular the muscle tone has been maintained as much as possible, and the fingers have not become stiff, and have therefore been able to regain their strength and usefulness.

3. Those who do not improve, but physiotherapy prevents the fingers tecoming further cletormed and contracted.

4. Those whose hands became worse, and with one or two exceptions, this has only occurred with patients who were irregular in attendance for tratment, or who only attended for a month or (wo).

\section{Rehabilitation.}

It is important that some rehabilitation programme be carried on at the same time as physiotherapy, so that the patient may have reasonable hope that he may become active, useful, ancl inclepenclent by his own efforts, and in this way he will clevelop a happier out- 
look towards the future. The occupation should be one which stimulates the active interest of the patient so that he looks forward to doing it. It should also be an occupation which will (lo him no harm. For instance, bamboo basket making has proved an unsuitable tracle, partly because much of the weaving depends upon touch reflexes, and many leprosy patients have no sense of touch, and so their hands continually suffer minor injuries from splinters when doing this type of work. But a trade such as simple carpentry has proved to be within the power of most patients, provicled some care is taken to see that the handles of all tools are adjusted where necessary to tit the strongest part of the grasp). The making of simple garments with a sewing machine also appears to be within the scope of their capabilities. Finally, the occupation should be one at which he can earn a living wage, so it is of great importance that patients should be shown how to make the best use of their hands, and taught tracles in which their skill and dexterity may compete on equal terms with others with normal hancls.

\section{AC.KNOWLEI)(iMENTS.}

I. We wish to thank the Indian Council of Medical Research for making this investigation possible.

2. We also wish to acknowledge gratefully the technical assistance rendered by Mr. R. Namasivayam in much of the letailed survey of the work clone.

\section{BIBLIOGRAPHY}

1. Cochranf, R. G., Practical Text-book of Leprosy. 19.47.

2. Muir, Ernfist, Mamual of Leprory. 19.48.

3. Bunnfle, Striling, Surgery of the Hand. 194.

4. Alderson, Stanlfy, Physical Therapy in Leprosy, Leproly Retieu. Vol. XIX, No. 4, Oct. 19.48 .

5. Brand, P. W., Rehabilitation for L.eprosy Patients, Leprosy in lndia. Vol. XXIII, No. 1. Jan. 1951.

6. Morris, Roxif, Comparison of Chronaxic and Manual Muscle Testing of Muscles Affected by Poliomyclitis, The Physial Therap'y Revieu. Vol. XXXI, No. 7, July 1951 .

7. Laughin, Eva M., Physical Thorapy in the National leprosarium, The Physical Theratpy Revieu'. Vol. XXXII, No. 1, Jan. 1952.

8. Fioyd, W. F., and Silver, P. H. S., Patterns of Muscle Activity in Posture and Movement, Physiotherat)y, Vol. XXXVIII, No. 3 March, 1952.

c. Ritchif, A. E., Electro-diagnosis-Routine or Research? Physiotberafy'. Vol. XXXVIII, No. 9, Sept. 1952.

10. Spurrell, W. R., Precision, Physiotheraty. Vol. XXXVIII, No. 9. Sept. 1952.

11. Pulvartaft, R. Guy, The Care of the Injured Hand, Physiotherapy. Vol. XXXVIII, No. 12, Dec. 1952.

12. Nerva Injurifs Committee, Aids to the Investigation of Peripheral Nerve Injuries, Medical Research Council (London). War Memorandum No. 7 Revised Second Edition 19.43.

13. Ciba Symposia. Vol. IV, N(). 4, July 19-\{2-The Hand.

14. Ciba Clinical Symposia, Vol. III, No. 8, Dec. 1951-Surgical Anatomy of the Hand.

15. Brand, P. W', Reconstruction of the Hand in Leprosy, Amnals of Roya! College of Surgeons of Ergland. Vol. II, Dec. 1952, PP. 35()-361. 